\title{
Erratum
}

\section{Erratum to "Reverse Zagreb and Reverse Hyper-Zagreb Indices for Crystallographic Structure of Molecules"}

\author{
Zhen Wang, ${ }^{1}$ Faryal Chaudhry, ${ }^{2}$ Maria Naseem, ${ }^{3}$ and Adnan Asghar $\mathbb{D}^{2}$ \\ ${ }^{1}$ School of Computer Engineering, Anhui Wonder University of Information Engineering, Hefei 231201, China \\ ${ }^{2}$ The University of Lahore, Lahore, Pakistan \\ ${ }^{3}$ University of Central Punjab, Lahore, Pakistan \\ Correspondence should be addressed to Adnan Asghar; adnan.asghar@math.uol.edu.pk \\ Received 13 May 2020; Accepted 14 May 2020; Published 27 June 2020 \\ Copyright ( $\odot 2020$ Zhen Wang et al. This is an open access article distributed under the Creative Commons Attribution License, \\ which permits unrestricted use, distribution, and reproduction in any medium, provided the original work is properly cited.
}

In the article titled "Reverse Zagreb and Reverse HyperZagreb Indices for Crystallographic Structure of Molecules" [1], 21 references were added by the authors to the reference list following editorial acceptance. A reassessment of the article by the editor confirmed that the following references should be removed from the article:

[18] W. Gao, M. Asif, and W. Nazeer, "The study of honey comb derived network via topological indices," Open Journal of Mathematical Analysis, vol. 2018, no. 2, pp. 10-26, 2018.

[21] M. Munir, W. Nazeer, S. Rafique, and S. Kang, "Mpolynomial and degree-based topological indices of polyhex nanotubes," Symmetry, vol. 8, no. 12, p. 149, 2016.

[22] M. Munir, W. Nazeer, A. Nizami, S. Rafique, and S. Kang, "M-polynomials and topological indices of titania nanotubes," Symmetry, vol. 8, no. 11, p. 117, 2016.

[23] Y. C. Kwun, M. Munir, W. Nazeer, S. Rafique, and S. M. Kang, "M-polynomials and topological indices of V-phenylenic nanotubes and nanotori," Scientific Reports, vol. 7, no. 1, pp. 1-9, 2017.

[27] W. Gao, A. Asghar, and W. Nazeer, "Computing degree-based topological indices of Jahangir graph," Engineering and Applied Science Letters, vol. 2018, no. 1, pp. 16-22, 2018.

[29] W. Gao, M. Younas, A. Farooq, A. Virk, and W. Nazeer, "Some reverse degree-based topological indices and polynomials of dendrimers," Mathematics, vol. 6, no. 10, p. 214, 2018.
[30] A. Ali, W. Nazeer, M. Munir, and S. Min Kang, "M-polynomials and topological indices of zigzag and rhombic benzenoid systems," Open Chemistry, vol. 16, no. 1, pp. 73-78, 2018.

[31] Y. C. Kwun, A. Ali, W. Nazeer, M. Ahmad Chaudhary, and S. M. Kang, "M-polynomials and degree-based topological indices of triangular, hourglass, and jagged-rectangle benzenoid systems," Journal of Chemistry, vol. 2018, 2018.

[32] W. Gao, M. Younas, A. Farooq, A. Mahboob, and W. Nazeer, "M-polynomials and degree-based topological indices of the crystallographic structure of molecules," Biomolecules, vol. 8, no. 4, p. 107, 2018.

[33] J.-B. Liu, M. Younas, M. Habib, M. Yousaf, and W. Nazeer, "M-polynomials and degree-based topological indices of VC5C7[p,q] and HC5C7[p,q] nanotubes," IEEE Access, vol. 7, pp. 41125-41132, 2019.

[34] Y. C. Kwun, A. Farooq, W. Nazeer, Z. Zahid, S. Noreen, and S. M. Kang, "Computations of the M-polynomials and degree-based topological indices for dendrimers and polyomino chains," International Journal of Analytical Chemistry, vol. 2018, 2018.

[35] S. M. Kang, M. A. Zahid, A. u. R. Virk, W. Nazeer, and W. Gao, "Calculating the degree-based topological indices of dendrimers," Open Chemistry, vol. 16, no. 1, pp. 681-688, 2018.

[36] W. Nazeer, A. Farooq, M. Younas, M. Munir, and S. Kang, "On molecular descriptors of carbon nanocones," Biomolecules, vol. 8, no. 3, p. 92, 2018. 
[38] M. A. Rehman, C. Shi, and W. Nazeer, "Useful irregularity indices in QSPR study for bismuth tri-iodide," Journal of Chemistry, vol. 2019, 2019.

[40] A. Farooq, M. Habib, A. Mahboob, W. Nazeer, and S. M. Kang, "Zagreb polynomials and redefined zagreb indices of dendrimers and polyomino chains," Open Chemistry, vol. 17, no. 1, pp. 1374-1381, 2009.

[42] M. K. Jamil, A. Javed, W. Nazeer, M. R. Farahani, and Y. Gao, "Four vertex-degree-based topological indices of VC 5 C 7[p; q] nanotubes," Communications in Mathematics and Applications, vol. 8, no. 1, pp. 99-105, 2017.

[45] Y. C. Kwun, M. A. Zahid, W. Nazeer, A. Ali, M. Ahmad, and S. M. Kang, "On the zagreb polynomials of benzenoid systems," Open Physics, vol. 16, no. 1, pp. 734-740, 2018.

[46] S. M. Kang, M. Yousaf, M. A. Zahid, M. Younas, and W. Nazeer, "Zagreb Polynomials and redefined Zagreb indices of nanostar dendrimers," Open Physics, vol. 17, no. 1, pp. 31-40, 2019.

[48] Z. Hussain, M. Munir, W. Nazeer, M. S. Saleem, S. M. Kang, and Y. C. Kwun, "Computational aspects of line graph of carbon nanocones," Journal of the National Science Foundation of Sri Lanka, vol. 47, no. 4, 2019.

[50] Y. J. Ge, J. B. Liu, M. Younas, M. Yousaf, and W. Nazeer, "Analysis of and nanotubes via topological indices," Journal of Nanomaterials, vol. 2019, 2019.

[52] W. Gao, B. Muzaffar, and W. Nazeer, "K-Banhatti and K-hyper Banhatti indices of dominating David Derived network," Open Journal of Mathematical Analysis, vol. 2017, no. 1, pp. 13-24, 2017.

\section{References}

[1] Z. Wang, F. Chaudhry, M. Naseem, and A. Asghar, "Reverse zagreb and reverse hyper-zagreb indices for crystallographic structure of molecules," Journal of Chemistry, vol. 2020, Article ID 9805829, 13 pages, 2020. 